\title{
Absorption and metabolism of red orange juice anthocyanins in rats
}

\author{
Catherine Felgines ${ }^{1}$, Séverine Talavéra ${ }^{1},{\text { Odile } \text { Texier }^{1} \text {, Catherine Besson }}^{2}$, Vincenzo Fogliano ${ }^{3}$, \\ Jean-Louis Lamaison ${ }^{1}$, Luca la Fauci ${ }^{4}$, Giacomo Galvano ${ }^{5}$, Christian Rémésy ${ }^{2}$ and Fabio Galvano ${ }^{4}$ \\ ${ }^{1}$ Laboratoire de Pharmacognosie, Faculté de Pharmacie, Clermont-Ferrand, France \\ ${ }^{2}$ Laboratoire des Maladies Métaboliques et des Micronutriments, Institut National de la Recherche Agronomique de \\ Clermont-Ferrand/Theix, France \\ ${ }^{3}$ Department of Food Science, University of Naples 'Federico II', Naples, Italy \\ ${ }^{4}$ Department of Agro-forestry and Environmental Science, Mediterranean University of Reggio Calabria, Italy \\ ${ }^{5}$ Department of Agronomical, Agrochemical and Animal Production Science, University of Catania, Italy
}

(Received 6 October 2005 - Revised 13 December 2005 - Accepted 14 December 2005)

\begin{abstract}
Anthocyanins are natural pigments that could be involved in various health effects. Red oranges are an important dietary source of anthocyanins, including cyanidin 3-glucoside (Cy 3-glc) and an acylated derivative, cyanidin 3-(6"-malonyl)-glucoside (Cy 3-malglc). The aim of this study was to evaluate the absorption and metabolism of red orange anthocyanins in rats fed an anthocyanin-enriched diet for $12 \mathrm{~d}$ (approximately $2.8 \mu \mathrm{mol}$ anthocyanins/d). Furthermore, the absorption of these anthocyanins was studied in both the stomach and intestine using in situ models in rats. Anthocyanin metabolites were identified and quantified by HPLC-electrospray ionization tandem MS and HPLC-diode array detection, respectively. The red orange anthocyanins, Cy 3-glc and Cy 3-malglc, as well as their respective methylated derivatives, were recovered in urine after red orange juice intake. The $24 \mathrm{~h}$ urinary excretion of total anthocyanins was low (0.081 (SEM 0.009) \% of the ingested amount). However, a high proportion (about 20\%) of red orange anthocyanins was absorbed from the stomach. More Cy 3malglc than $\mathrm{Cy}$ 3-glc was absorbed in the intestine. This study thus indicated that red orange juice anthocyanins were rapidly absorbed from both stomach and small intestine, and then excreted in the urine as intact and methylated forms. Moreover, the absorption and metabolism of acylated anthocyanins and non-acylated anthocyanins were similar.
\end{abstract}

Red orange anthocyanins: Rat: Absorption: Metabolism: Acylation

Anthocyanins (from the Greek antos, flower, and kyanos, blue) are natural pigments widely distributed in fruits. They are important in nutrition because their daily intake, which is estimated at around $200 \mathrm{mg}$ in the USA, is higher than that of other flavonoids (Kühnau, 1976). Anthocyanins play a role in a wide range of biological activities. They may reduce the risk of coronary heart disease (Renaud \& de Lorgeril, 1992), reduce inflammatory insult (Youdim et al. 2002), modulate the immune response (Wang \& Mazza, 2002) and exert anticarcinogenic activities in vitro (Fimognari et al. 2004). These actions might be mediated by their antioxidant activity (Tsuda et al. 1998; Mazza et al. 2002) owing to their particular chemical structure, which is characterized by an electron deficiency making them particularly reactive to reactive oxygen species (Galvano et al. 2004).

Although numerous studies have evaluated the absorption and metabolism of anthocyanin glycosides (Miyazawa et al. 1999; Tsuda et al. 1999; Bub et al. 2001; Cao et al. 2001; Matsumoto et al. 2001; Felgines et al. 2002; Wu et al. 2002; Frank et al. 2003; McGhie et al. 2003; Nielsen et al.
2003; Bitsch et al. 2004; Cooney et al. 2004; Ichiyanagi et al. 2004, 2005; Kay et al. 2004; Talavéra et al. 2006), only a few reports are available on the absorption and metabolism of acylated anthocyanins (Suda et al. 2002; Harada et al. 2004). However, these acylated compounds are present in a number of edible plants, including red oranges, red cabbage and purple sweet potatoes (Giusti \& Wrolstad, 2003; Galvano et al. 2004). Pigmented oranges (Citrus sinensis varieties: Moro, Tarocco and Sanguinello), also known as 'red' or 'blood' oranges and typically grown in the Etna volcano region of Sicily (Italy) as well as in Florida (USA), are an important dietary source of anthocyanins such as cyanidin 3-glucoside (Cy 3-glc) and cyanidin 3-(6"-malonyl)-glucoside (Cy 3-malglc), responsible for their brilliant red colour. However, no data are available on the bioavailability of red orange juice anthocyanins. Thus, the aim of this study was to evaluate the absorption and metabolism of red orange juice anthocyanins in rats fed for $12 \mathrm{~d}$ with an anthocyaninenriched diet ('adapted rats'). In addition, the absorption of these anthocyanins was studied using in situ models in rats (Talavéra et al. 2003, 2004). 


\section{Materials and methods}

Chemicals

Cy 3-glc and cyanidin 3,5-diglucoside were purchased from Extrasynthèse (Genay, France). Red orange juice lyophilisate was supplied by Liofil S.r.l. (Ribera, Sicily, Italy).

\section{Animals and diets}

'Adapted rat' study. Twelve male Wistar rats (Iffa-Credo, L'Arbresle, France) weighing approximately $200 \mathrm{~g}$ were housed two per cage in temperature-controlled rooms $\left(22^{\circ} \mathrm{C}\right)$, with the a controlled dark period from 08.00 to $20.00 \mathrm{~h}$ and access to food from 08.00 to $16.00 \mathrm{~h}$. They were fed a semi-purified control diet $(755 \mathrm{~g} / \mathrm{kg}$ wheat starch, $150 \mathrm{~g} / \mathrm{kg}$ casein, $50 \mathrm{~g} / \mathrm{kg}$ peanut oil, $35 \mathrm{~g} / \mathrm{kg}$ AIN-93M mineral mixture, $10 \mathrm{~g} / \mathrm{kg}$ AIN-76A vitamin mixture) for $6 \mathrm{~d}$ (Felgines et al. 2002). They were then individually housed in metabolic cages fitted with urine-faeces separators and received the control diet supplemented with red orange juice lyophilisate $(200 \mathrm{~g} / \mathrm{kg}$ diet) for $12 \mathrm{~d}$. The rats ate approximately $16.5 \mathrm{~g} / \mathrm{d}$ diet, i.e. approximately $3.3 \mathrm{~g} / \mathrm{d}$ red orange juice lyophilisate. To quantify dietary anthocyanin content, red orange juice lyophilisate $(1 \mathrm{~g})$ was treated for $30 \mathrm{~min}$ under agitation with $45 \mathrm{ml}$ methanol-water $(50: 50 \mathrm{v} / \mathrm{v})$. After filtration, the volume of solution was adjusted to $50 \mathrm{ml}$, and this solution was diluted twice with $0.12 \mathrm{M}-\mathrm{HCl}$ before HPLC analysis $(20 \mu \mathrm{l})$ as described below.

In situ experiments. Twelve male Wistar rats (Iffa-Credo) weighing approximately $200 \mathrm{~g}$ were housed two per cage in temperature-controlled rooms $\left(22^{\circ} \mathrm{C}\right)$, with a controlled dark period from 20.00 to $08.00 \mathrm{~h}$ and access to food from 16.00 to $08.00 \mathrm{~h}$. They were fed the semi-purified control diet for 2 weeks.

All animals were maintained and handled according to the recommendations of the Institutional Ethic Committee (INRA), in accordance with French decree No 87-848.

\section{Sampling procedure during 'adapted rat' study}

Rats were killed $3 \mathrm{~h}$ or $6 \mathrm{~h}$ after the beginning of the last experimental meal (i.e. at $11.00 \mathrm{~h}$ and $14.00 \mathrm{~h}$, respectively) after being anaesthetised with sodium pentobarbital ( $40 \mathrm{mg} / \mathrm{kg}$ body weight). Blood was withdrawn from the abdominal aorta into heparinised tubes. Plasma was acidified with $240 \mathrm{~mm}-\mathrm{HCl}$. Urine present in the bladder was collected and acidified with $240 \mathrm{~mm}-\mathrm{HCl}$. The day before the rats were killed, urine was collected over $24 \mathrm{~h}$ in tubes containing $1 \mathrm{ml}$ $1.8 \mathrm{M}-\mathrm{HCl}$. Collecting urine on $\mathrm{HCl}$ allowed a regeneration of the coloured structure of anthocyanins and thus increased their stability. We previously ensured that Cy 3-malglc was stable in these acidic conditions. Caecal contents were drained by finger pressure into microfuge tubes. All samples were rapidly frozen and stored at $-20^{\circ} \mathrm{C}$ until analysis.

\section{Anthocyanin administration during in situ experiments}

Rats fasted for $24 \mathrm{~h}$ were anaesthetised with sodium pentobarbital $(40 \mathrm{mg} / \mathrm{kg}$ body weight, intraperitoneal injection) and kept alive under anaesthesia throughout the experiments.

In situ gastric administration. After cannulation of the bile duct, the pylorus was ligated and a physiological buffer was injected into the stomach across the cardia. This sphincter was ligated to prevent any gastro-oesophageal reflux. The stomach was filled in situ with $5 \mathrm{ml}$ of a buffer specially developed to mimic the osmotic and $\mathrm{pH}$ conditions found in the stomach during a meal. This buffer $(\mathrm{pH} 3)$ contained $\mathrm{KH}_{2} \mathrm{PO}_{4}$ (7.5 mM), $\mathrm{NaCl}(50 \mathrm{~mm}), \mathrm{KCl}(50 \mathrm{~mm}), \mathrm{CaCl}_{2}$ $(2 \mathrm{mM})$, acetic acid $(25 \mathrm{~mm})$, lactic acid $(25 \mathrm{~mm}), \mathrm{MgSO}_{4}$ $(1 \mathrm{mM})$ and polyethylene glycol $6000(5 \mathrm{~g} / \mathrm{l})$ and was maintained at $37^{\circ} \mathrm{C}$ (Talavéra et al. 2003). It was supplemented with approximately $22 \mu \mathrm{mol} / \mathrm{l}$ of red orange juice anthocyanins. The amounts of anthocyanins infused into the stomach (about $110 \mathrm{nmol}$ ) were consistent with those previously used in similar models (Crespy et al. 2002; Passamonti et al. 2003; Talavéra et al. 2003). Red orange anthocyanin extract was obtained as described later. At $30 \mathrm{~min}$ after administration, the stomach contents were collected and blood samples were withdrawn from the abdominal aorta into heparinised tubes. Bile was collected throughout the $30 \mathrm{~min}$ of the experiment. Plasma and bile samples were acidified with $240 \mathrm{mM}-\mathrm{HCl}$, whereas the stomach contents were acidified with $40 \mathrm{~mm}-\mathrm{HCl}$. All samples were stored at $-20^{\circ} \mathrm{C}$ until analysis.

In situ intestinal perfusion. After cannulation of the bile duct, a perfusion of the jejunoileal segment of the intestine (from $5 \mathrm{~cm}$ distal to the duodenojejunal flexure up to the ileocaecal valve) was prepared by installing cannulas at each extremity. This segment was continuously perfused in situ for $45 \mathrm{~min}$ at a flow rate of $0.75 \mathrm{ml} / \mathrm{min}$ with a buffer containing $\mathrm{KH}_{2} \mathrm{PO}_{4}(5 \mathrm{mM})$, $\mathrm{K}_{2} \mathrm{HPO}_{4}(2.5 \mathrm{~mm}), \mathrm{NaHCO}_{3}(5 \mathrm{~mm}), \mathrm{NaCl}(50 \mathrm{~mm}), \mathrm{KCl}$ (40 mM), $\mathrm{CaCl}_{2}$ (2 mM), $\mathrm{MgSO}_{4}(1 \mathrm{~mm}), \mathrm{K}_{3} \mathrm{C}_{6} \mathrm{H}_{5} \mathrm{O}_{7}$ (10 mM), glucose $(12 \mathrm{mM})$, glutamine $(2 \mathrm{mM})$ and taurocholic acid (1 mM), pH 6.6, at $37^{\circ} \mathrm{C}$ (Talavéra et al. 2004). The buffer was supplemented with approximately $22 \mu \mathrm{mol} / 1$ of red orange anthocyanins. Red orange anthocyanin extract was obtained as described later. The intestine was washed of its contents during the first $25 \mathrm{~min}$. Effluents were directly collected at the exit of the ileum during the last 5 min of perfusion. Effluent volume was estimated by weighing. Bile was collected throughout the $45 \mathrm{~min}$ of the experiment. At the end of the experiment, blood samples were withdrawn from the abdominal aorta into heparinised tubes. Urine present in the bladder was also collected. Perfused solution, effluent, bile, plasma and urine samples were rapidly acidified with $240 \mathrm{~mm}-\mathrm{HCl}$ and stored at $-20^{\circ} \mathrm{C}$ until analysis.

To determine the stability of anthocyanins throughout the in situ perfusion experiment (at $37^{\circ} \mathrm{C}, \mathrm{pH} \mathrm{6.6)}$, an aliquot of the perfused buffer maintained at $37^{\circ} \mathrm{C}$ was collected at the beginning $(\mathrm{t}=0)$, at $\mathrm{t}=25 \mathrm{~min}$ and at the end $(\mathrm{t}=45 \mathrm{~min})$ of the perfusion period, and the anthocyanins were analysed by HPLC after acidification with $240 \mathrm{~mm}-\mathrm{HCl}$, as described later. The overall percentage of degradation was calculated by the decrease in anthocyanin concentrations between 0 and $45 \mathrm{~min}$. Moreover, anthocyanin degradation was a linear function of time. Thus, the amounts of anthocyanin perfused were determined from the mean of the anthocyanin concentrations in the perfused buffer at $\mathrm{t}=0$ and $\mathrm{t}=45 \mathrm{~min}$.

Red orange anthocyanin extract was prepared from red orange juice lyophilisate. It was obtained from $40 \mathrm{~g}$ powder treated for $30 \mathrm{~min}$ under agitation with $400 \mathrm{ml}$ methanol and then filtered. The filtrate was evaporated to dryness using a rotary evaporator at $35^{\circ} \mathrm{C}$, and then dissolved in 
$20 \mathrm{ml} 0 \cdot 12 \mathrm{M}-\mathrm{HCl}$ and briefly sonicated. The solution was centrifuged for $5 \mathrm{~min}$ at $12000 \mathrm{~g}$ at room temperature, and the supernatant was later diluted 20 -fold in the gastric or intestinal buffer to obtain a final concentration of approximately $22 \mu \mathrm{mol} / \mathrm{l}$ Cy 3-glc equivalents.

\section{Sample preparation}

Anthocyanins present in the urine samples were extracted using a solid phase extraction cartridge (Sep-Pak $\mathrm{C}_{18}$ Plus; Waters, Milford, MA, USA), as follows. The cartridge was washed with $10 \mathrm{ml}$ methanol and equilibrated with $10 \mathrm{ml}$ $12 \mathrm{~mm}$-aqueous $\mathrm{HCl}$ before use. Twenty-four-hour urine samples spiked with $3 \mathrm{nmol}$ cyanidin 3,5-diglucoside as an internal standard were loaded onto the cartridge. The cartridge was then washed with $10 \mathrm{ml} 12 \mathrm{~mm}$-aqueous $\mathrm{HCl}$, and anthocyanins were eluted with $3 \mathrm{ml} 12 \mathrm{mM}-\mathrm{HCl}$ in methanol. The methanolic extract was evaporated to dryness under reduced pressure using a rotary evaporator at $35^{\circ} \mathrm{C}$. The dried extract was dissolved with $300 \mu \mathrm{l} 0 \cdot 12 \mathrm{M}$-aqueous $\mathrm{HCl}$. After centrifugation for $5 \mathrm{~min}$ at $12000 \mathrm{~g}$, the supernatant $(60 \mu \mathrm{l})$ was analysed by HPLC as described below.

Caecal contents $(0.2 \mathrm{~g})$ were extracted with $1.8 \mathrm{ml}$ of water-acetone $(1: 1 \mathrm{v} / \mathrm{v})$ containing $500 \mathrm{mM}-\mathrm{HCl}$, and then briefly sonicated and centrifuged for $5 \mathrm{~min}$ at $12000 \mathrm{~g}$ at room temperature. Supernatants were evaporated under a stream of $\mathrm{N}_{2}$ gas to half their initial volume to eliminate the acetone. Finally, aqueous extracts $(60 \mu \mathrm{l})$ were analysed for anthocyanin content as described later.

Stomach contents were centrifuged for $5 \mathrm{~min}$ at room temperature, and then filtered on fritted glass and analysed $(20 \mu \mathrm{l})$ by HPLC. Absorption through the gastric wall was estimated by the difference between the amount of anthocyanins administered into the stomach and the amount recovered at the end of incubation.

After centrifugation for $5 \mathrm{~min}$ at $12000 \mathrm{~g}$, the supernatants of intestinal effluents were analysed $(20 \mu \mathrm{l})$ by HPLC as described later. All the concentrations measured in the effluent samples were corrected by taking into account the intestinal absorption of water. Water absorption was estimated by calculating the difference between effluent flow and perfusion flow $(0.75 \mathrm{ml} /$ min). Absorption through the intestinal barrier was estimated by calculating the difference between the amount of anthocyanins administered through the intestinal segment and the amount recovered at the end of the ileal segment. These amounts were determined for the last $5 \mathrm{~min}$ of perfusion. Anthocyanin stability was also taken into account in evaluating intestinal absorption.

\section{HPLC analysis}

Quantification of anthocyanins was performed by HPLC using a photodiode array detector (DAD 200; Perkin Elmer, Courtabœuf, France) and a UV-visible detector (785A; Perkin Elmer) at $524 \mathrm{~nm}$. Samples were loaded onto a $150 \mathrm{~mm} \times 4.6 \mathrm{~mm}$ Hypersil C18-5 $\mu \mathrm{m}$ column protected by a $10 \times 4 \mathrm{~mm}$ Hypersil C18-5 $\mathrm{m}$ guard column (Interchim, Montluçon, France) and analysed as previously described (Felgines et al. 2002). Anthocyanin quantification was expressed as Cy 3-glc equivalents.

Red orange anthocyanins and anthocyanin metabolites were identified by HPLC-electrospray ionization tandem MS analysis. These analyses were performed on a Hewlett-Packard HPLC system equipped with MS-MS detection (API 2000; Applied Biosystems, Les Ulis, France) as previously described (Felgines et al. 2003). The MS data were collected in multiple reaction monitoring mode by monitoring the transition of parent and product ions specific for each compound, using a dwell time of $0.5 \mathrm{~s}$. Anthocyanins were detected according to the respective $\mathrm{m} / \mathrm{z}$, values of their parent and product ions: Cy 3-glc, 449/287; Cy 3-malglc, 535/287; methyl Cy 3-glc, 463/301; methyl Cy 3-malglc, $549 / 301$

\section{Polyethylene glycol measurements}

Polyethylene glycol, a compound that is not absorbed by the stomach, was added to the gastric buffer. Its concentration in the gastric buffer was determined by the method of Powell and Malawer (1968). The ratio between the initial concentration and that measured at the end of the experiment reflected the intensity of gastric secretion (gastric volume at the end of the experiment: approximately $5.8 \mathrm{ml}$ ). This parameter has to be taken into account in order to obtain the correct concentration of anthocyanins at the end of the experiment.

\section{Data analysis}

Values are given as means with their standard errors. When appropriate, significance of differences between values was determined by unpaired $t$ test (GraphPad; Instat, San Diego, CA, USA). Values of $P<0.05$ were considered significant.

\section{Results}

'Adapted rat' study

The HPLC profile of red orange juice lyophilisate showed two main peaks as well as other smaller ones (Fig. 1(a)). Peaks 1

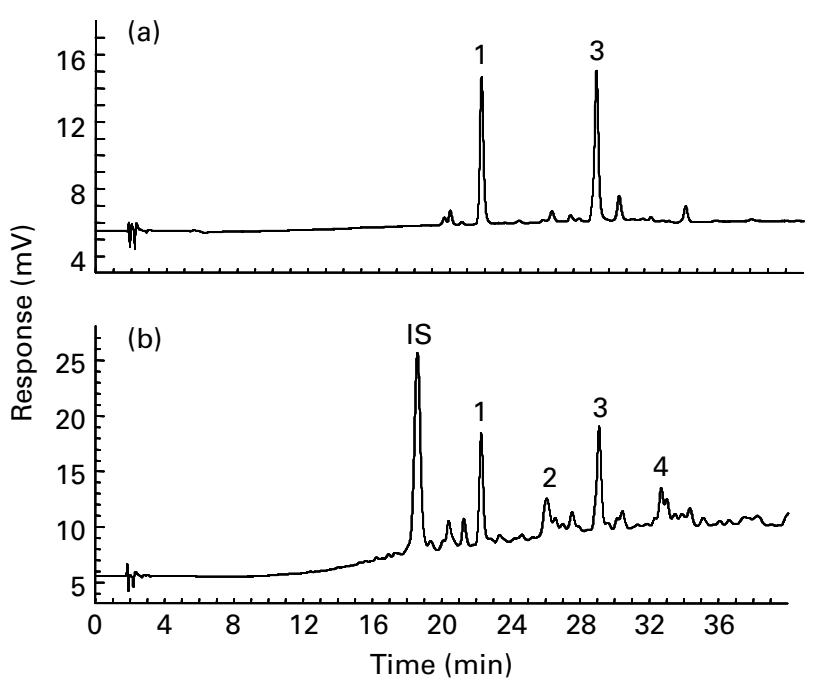

Fig. 1. HPLC chromatogram of red orange juice lyophilisate (a) and $24 \mathrm{~h}$ urine from rats fed red orange juice (b). Detection was performed at $524 \mathrm{~nm}$. IS, internal standard (cyanidin 3,5-diglucoside). Peaks are as follows: (1) cyanidin 3-glucoside, (2) methyl cyanidin 3-glucoside, (3) cyanidin 3-malonylglucoside, (4) methyl cyanidin 3-malonylglucoside. 
and 3 were identified as $\mathrm{Cy} 3$-glc and $\mathrm{Cy} 3$-malglc, respectively. Concentrations of $\mathrm{Cy} \mathrm{3-glc} \mathrm{and} \mathrm{Cy} 3-\mathrm{malglc}$ in the anthocyanin-supplemented diet were $74.4 \mu \mathrm{mol} / \mathrm{kg}$ and $90.4 \mu \mathrm{mol} / \mathrm{kg}$, respectively. Therefore, rats ate approximately $1.23 \mu \mathrm{mol} / 24 \mathrm{~h}$ and $1.50 \mu \mathrm{mol} / 24 \mathrm{~h}$ of $\mathrm{Cy} 3$-glc and $\mathrm{Cy}$ 3-malglc, respectively.

Several peaks were detected in the urine from red orange anthocyanin-fed rats (Fig. 1(b)). Urine collected in the bladder and $24 \mathrm{~h}$ urine both presented the same HPLC profile. The urinary HPLC profile showed red orange juice anthocyanins as well as methylated derivatives. The presence of red orange anthocyanins, Cy 3-glc (peak 1) and Cy 3-malglc (peak 3) was confirmed by HPLC-electrospray ionization tandem MS analysis by detection of their specific parent and product ions $(\mathrm{m} / \mathrm{z}$ values 449/287 and 535/287, respectively; Fig. 2(c), (e)). Peak 2 was identified as methyl Cy 3 -glc according to its parent and product ion pair (463/301; Fig. 2(d)). Peak 4 displayed a parent and product ion pair at $m / z 549 / 301$, suggesting the presence of methyl Cy 3-malglc (Fig. 2(f)). The mean urinary excretion of anthocyanins over a $24 \mathrm{~h}$ period was estimated taking account of these four major peaks (Table 1). The data demonstrated that only a negligible amount of the anthocyanins (below $0.1 \%$ ) was recovered in the urine.

The caecal contents contained Cy 3-glc and Cy 3-malglc as well as the other red orange juice anthocyanins (Fig. 3). A low amount of cyanidin was also recovered. Total caecal anthocyanins and cyanidin contents were 12.5 (SEM 2.0) nmol and 15.9 (SEM 2.2) nmol $(n$ 6) at 3 and $6 \mathrm{~h}$ after the beginning of the last meal, respectively. Caecal Cy 3-glc content was significantly higher at $6 \mathrm{~h}$ than at $3 \mathrm{~h}(P<0 \cdot 05)$.

In situ gastric administration

We first ensured that red orange anthocyanins were stable under the experimental conditions, i.e. incubated for $30 \mathrm{~min}$ at $37^{\circ} \mathrm{C}$ in the gastric buffer $(\mathrm{pH} 3)$.

About $20 \%$ of the anthocyanins were absorbed from the gastric lumen (Table 2). Absorption of $\mathrm{Cy} 3$-glc at the gastric level was not significantly different from that of $\mathrm{Cy} 3$-malglc. No metabolites of anthocyanins were observed in the stomach contents after $30 \mathrm{~min}$ of incubation. HPLC analysis of urine revealed the presence of native red orange juice anthocyanins (Cy 3-glc, Cy 3-malglc) as well as their methylated derivatives. The low doses infused did not enable the detection of metabolites in either bile or plasma.

\section{In situ intestinal perfusion}

The overall percentage of anthocyanin degradation during the 45 min of perfusion was less than $2 \%$.

HPLC profiles were similar between the effluents and the red orange anthocyanin extract perfused. Absorption from the intestinal lumen was about $10 \%$ (Table 3), and there was a higher intestinal absorption of Cy 3-malglc than Cy 3-glc $(P<0 \cdot 05)$. Red orange anthocyanins as well as their methylated derivatives were detected in urine collected after in situ intestinal perfusion. No anthocyanin was detected in plasma or bile samples owing to the low amount of anthocyanins perfused.
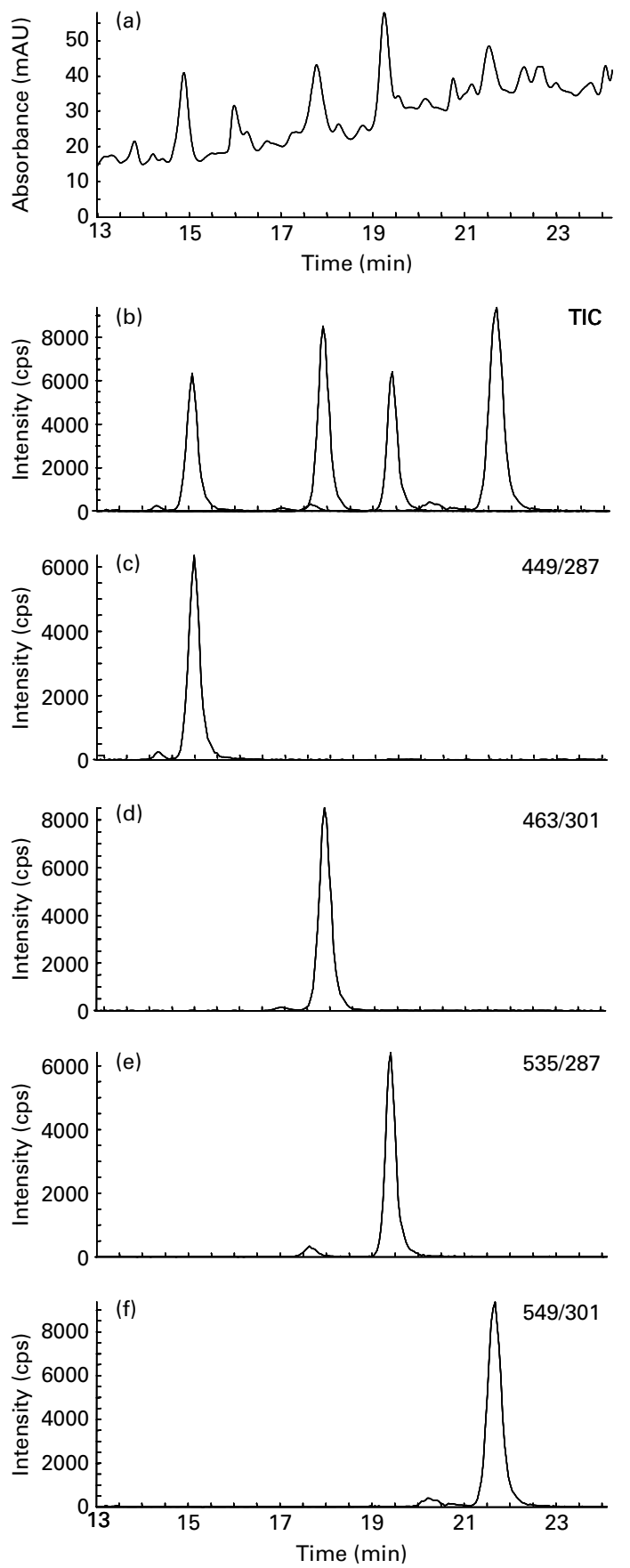

Fig. 2. HPLC-electrospray ionization tandem MS analysis of anthocyanin metabolites in urine from rats fed red orange juice. (a) Detection at $524 \mathrm{~nm}$. Detection of the respective $\mathrm{m} / \mathrm{z}$ values of the parent and product ions: (b) total ionic current (TIC), (c) cyanidin 3-glucoside, (d) methyl cyanidin 3-glucoside, (e) cyanidin 3-malonylglucoside, (f) methyl cyanidin 3-malonylglucoside.

\section{Discussion}

The aim of this study was to evaluate the bioavailability and sites of absorption of anthocyanins contained in red oranges. A preliminary step involved determining the anthocyanin content of the red orange juice lyophilisate used in these experiments. The red orange juice contained two major anthocyanins, Cy 3-glc and Cy 3-malglc, as previously reported 
Table 1. Urinary anthocyanin excretion following ingestion of red orange anthocyanins

(Means and their standard errors, $n$ 9)

\begin{tabular}{|c|c|c|c|c|c|c|}
\hline \multirow[b]{3}{*}{ Compound } & \multirow{2}{*}{\multicolumn{2}{|c|}{$\begin{array}{l}\text { Anthocyanin } \\
\text { ingestion } \\
(\mu \mathrm{mol} / 24 \mathrm{~h})\end{array}$}} & \multicolumn{4}{|c|}{ Urinary anthocyanin excretion } \\
\hline & & & \multicolumn{2}{|c|}{ (nmol/24 h) } & \multicolumn{2}{|c|}{$\begin{array}{c}\text { (\% of amount } \\
\text { ingested) }\end{array}$} \\
\hline & Mean & SEM & Mean & SEM & Mean & SEM \\
\hline Cy 3-glc & $1 \cdot 23$ & 0.05 & 0.71 & 0.14 & 0.057 & 0.011 \\
\hline Methyl Cy 3-glc & & & 0.47 & 0.05 & $0.038 \dagger$ & 0.003 \\
\hline Cy 3-malglc & 1.50 & 0.06 & 0.68 & 0.12 & 0.045 & 0.008 \\
\hline Methyl Cy 3-malglc & & & 0.38 & 0.08 & $0.025 \ddagger$ & 0.004 \\
\hline Total anthocyanins & 2.73 & 0.11 & $2 \cdot 24$ & 0.29 & 0.081 & 0.009 \\
\hline
\end{tabular}

Cy 3-glc, cyanidin 3-glucoside; Cy 3-malglc, cyanidin 3-(6"-malonyl)-glucoside. † Related to Cy 3-glc ingestion.

$\ddagger$ Related to Cy 3-malglc ingestion.

(Lee, 2002; Dugo et al. 2003; Hillebrand et al. 2004). These two pigments accounted for more than $82 \%$ of the total anthocyanins.

Although numerous studies have focused on anthocyanin glycoside bioavailability (Miyazawa et al. 1999; Tsuda et al. 1999; Bub et al. 2001; Cao et al. 2001; Matsumoto et al. 2001; Felgines et al. 2002; Wu et al. 2002; Frank et al. 2003; McGhie et al. 2003; Nielsen et al. 2003; Bitsch et al. 2004; Cooney et al. 2004; Ichiyanagi et al. 2004, 2005; Kay et al. 2004; Talavéra et al. 2006), there have been very few attempts to evaluate the absorption and metabolism of acylated anthocyanins. Previous studies have investigated only the absorption of complex acylated anthocyanins from purple sweet potato in rats receiving a single bolus of anthocyanins by gavage (Suda et al. 2002; Harada et al. 2004). Our study reports the first information on the urinary excretion of acylated anthocyanins after the adaptation of rats to an anthocyanin-enriched diet for $12 \mathrm{~d}$. This model mimics a regular intake of anthocyanins. Expressed as dry weight, rats eat approximately $20 \mathrm{~g} / \mathrm{d}$ diet whereas humans eat in the region of $400 \mathrm{~g} / \mathrm{d}$ food. Therefore the consumption of approximately $3.3 \mathrm{~g} / \mathrm{d}$ red orange juice lyophilisate by rats would correspond to about $66 \mathrm{~g} / \mathrm{d}$ in human subjects, i.e. about



Fig. 3. Caecal anthocyanin contents of rats fed red orange juice anthocyanins. Values are means with their standard errors, shown by vertical bars $(n 6)$. ${ }^{\star} P<0.05$. घ, Cyanidin 3-glucoside; $\square$, Cyanidin 3-(6" malonyl)-glucoside; $\square$, Cyanidin; $\square$, Other anthocyanins
Table 2. Anthocyanin absorption after a $30 \mathrm{~min}$ administration of red orange anthocyanins into the stomach of rats

(Means and their standard errors, $n 5$ )

\begin{tabular}{|c|c|c|c|c|c|c|}
\hline \multirow[b]{2}{*}{ Compound } & \multicolumn{2}{|c|}{$\begin{array}{l}\text { Anthocyanins } \\
\text { injected into } \\
\text { the gastric } \\
\text { lumen (nmol) }\end{array}$} & \multicolumn{2}{|c|}{$\begin{array}{l}\text { Anthocyanins } \\
\text { absorbed from } \\
\text { the gastric } \\
\text { lumen (nmol) }\end{array}$} & \multicolumn{2}{|c|}{$\begin{array}{l}\text { Anthocyanin } \\
\text { absorption } \\
\text { from the gas- } \\
\text { tric lumen (\% } \\
\text { of the injected } \\
\text { dose) }\end{array}$} \\
\hline & Mean & SEM & Mean & SEM & Mean & SEM \\
\hline Cy 3-glc & $52 \cdot 8$ & 0.5 & $11 \cdot 1$ & 1.5 & $20 \cdot 9$ & $2 \cdot 7$ \\
\hline Cy 3-malglc & $55 \cdot 3$ & 0.3 & 9.85 & $1 \cdot 21$ & $17 \cdot 8$ & $2 \cdot 2$ \\
\hline
\end{tabular}

Cy 3-glc, cyanidin 3-glucoside; Cy 3-malglc, cyanidin 3-(6"-malonyl)-glucoside.

$660 \mathrm{ml}$ red orange juice since the dry content of this juice is approximately $100 \mathrm{~g} / \mathrm{l}$. Such an amount can easily be consumed daily by humans. Red orange juice anthocyanins were recovered in the urine and were accompanied by methylated derivatives of both Cy 3-glc and Cy 3-malglc. These methylated conjugates could result from hepatic methylation at the $3^{\prime}$ hydroxyl moiety position of cyanidin derivatives by catechol $O$-methyltransferase, as previously described (Felgines et al. 2002; Ichiyanagi et al. 2005; Talavéra et al. 2005).

The percentage of red orange anthocyanins and their methylated derivatives recovered in the urine (calculated as the ratio of anthocyanins excreted to anthocyanins ingested) was low (about $0.08 \%$ ). Given that the methyl Cy 3-glc and methyl Cy 3-malglc found in the urine resulted from the methylation of $\mathrm{Cy} 3$-glc and $\mathrm{Cy}$ 3-malglc, respectively, their excretion could be linked to the ingestion of $\mathrm{Cy} \mathrm{3-glc} \mathrm{and}$ Cy 3-malglc. We can thus consider that the urinary recovery of Cy 3-glc and Cy 3-malglc as either the intact or the methylated forms was in the region of $0.095 \%$ and $0.070 \%$ of the ingested amounts, respectively. Although there are scarce quantitative data on the urinary excretion of anthocyanins in rats, the urinary recovery of red orange anthocyanins was of the same order of magnitude as previously reported (Felgines et al. 2002; Harada et al. 2004; Talavéra et al. 2006). Moreover, these results clearly show that acylation did not affect the absorption, metabolism or excretion of anthocyanins. In the present study, we failed to detect

Table 3. Anthocyanin absorption after perfusion of red orange anthocyanins through the intestinal lumen of rats

(Means and their standard errors, $n 5$ )

\begin{tabular}{|c|c|c|c|c|c|c|}
\hline \multirow[b]{2}{*}{ Compound } & \multicolumn{2}{|c|}{$\begin{array}{l}\text { Anthocyanins } \\
\text { perfused } \\
\text { through the } \\
\text { intestinal } \\
\text { lument (nmol) }\end{array}$} & \multicolumn{2}{|c|}{$\begin{array}{l}\text { Anthocyanins } \\
\text { absorbed from } \\
\text { the intestinal } \\
\text { lument (nmol) }\end{array}$} & \multicolumn{2}{|c|}{$\begin{array}{l}\text { Anthocyanin } \\
\text { absorption } \\
\text { from the intes- } \\
\text { tinal lumen (\% } \\
\text { of the perfused } \\
\text { dose) }\end{array}$} \\
\hline & Mean & SEM & Mean & SEM & Mean & SEM \\
\hline Cy 3-glc & $65 \cdot 2$ & $11 \cdot 0$ & $4 \cdot 31$ & 0.52 & $6 \cdot 79$ & 0.37 \\
\hline Cy 3-malglc & 69.9 & 11.7 & $9 \cdot 40^{*}$ & 1.85 & $13 \cdot 3^{*}$ & 0.6 \\
\hline
\end{tabular}

Cy 3-glc, cyanidin 3-glucoside; Cy 3-malglc, cyanidin 3-(6"-malonyl)-glucoside. Mean value was significantly different from that for Cy 3 -glc: ${ }^{*} P<0.05$. t These amounts correspond to the last $5 \mathrm{~min}$ of perfusion. 
glucurono-conjugates of anthocyanins in the urine. This was probably due to the low amounts of anthocyanins present in the diet. Indeed, we have previously identified cyanidin and peonidin monoglucuronides in urine from rats that had ingested 80-fold higher anthocyanin contents than in the present study, but these metabolites were present only in very small proportions (Talavéra et al. 2005).

Analysis of anthocyanins in the caecal contents revealed the presence of red orange anthocyanins as well as cyanidin. We have previously recovered glycosides as well as their corresponding aglycones in caecal contents from blackberry or bilberry anthocyanin-fed rats (Felgines et al. 2002; Talavéra et al. 2006). Cyanidin probably resulted from the hydrolysis of anthocyanins by caecal microflora glycosidases (Griffiths \& Smith, 1972) as red orange juice did not contain this aglycone. The instability of anthocyanidins at a physiological $\mathrm{pH}$ (near neutrality) was probably responsible for the low cyanidin content in the caecum, and cyanidin was probably rapidly transformed to non-coloured and/or degradation products, as recently suggested (Felgines et al. 2002; Fleschhut et al. 2006; Talavéra et al. 2006). Furthermore, the rats were adapted to the anthocyanin diet for $12 \mathrm{~d}$. The recovery of low amounts of red orange anthocyanins could result from adaptation of the microflora to anthocyanin degradation, as previously shown in rats adapted to flavanone-enriched diets (Felgines et al. 2000). The proportion of anthocyanin glucosides in the caecum was slightly different from that of the red orange juice. The Cy 3-glc to Cy 3-malglc ratio in red orange juice was 45:55. Six hours after the beginning of the last meal, this caecal content ratio was 61:39. Acylated $\mathrm{Cy}$ 3 -glc could be less stable at caecal $\mathrm{pH}$ or more sensitive to enzymatic degradation by microflora than Cy 3-glc. Moreover, the degradation of Cy 3-malglc by microflora could lead to the formation of Cy 3-glc. Indeed, Fleschhut et al. (2006) have shown that human faecal microflora were able to hydrolyse acylated groups from acylated anthocyanins.

To gain further insight into the behaviour of acylated anthocyanins, we investigated red orange anthocyanin absorption in the stomach and intestine using low, physiological amounts of anthocyanin. Gastric absorption was evaluated after direct administration of red orange anthocyanins (about $110 \mathrm{nmol}$ ) into the rat stomach using an in situ gastric administration model (Talavéra et al. 2003). Intestinal anthocyanin absorption was investigated using in situ intestinal (jejunoileal) perfusion as previously described (Talavéra et al. 2004). Our results indicated that a high proportion (about $20 \%$ ) of red orange anthocyanins was rapidly absorbed from the stomach. Moreover, absorption levels were close to those of previous reports for various anthocyanin monoglucosides under the same conditions (Talavéra et al. 2003). The acylation of Cy 3-glc did not modify its gastric absorption. We have previously shown that anthocyanins are absorbed across the stomach as intact forms (Talavéra et al. 2003, 2005). The mechanism of anthocyanin permeation in this organ remains unknown. Passamonti et al. (2002) suggested that bilitranslocase, which is an organic anion carrier expressed in the gastric epithelium, could be involved in the gastric absorption of anthocyanins. These authors have reported that the acylation of anthocyanin glucosides weakened the interaction between the anthocyanins and the bilitranslocase transport site. However, our results did not reveal differences between $\mathrm{Cy}$ 3-glc and Cy 3-malglc gastric absorption. The absorption and further metabolism of Cy 3-glc and Cy 3-malglc occurred very quickly, since native as well as methylated anthocyanins were recovered in the urine only $30 \mathrm{~min}$ after the beginning of the experiment.

On the other hand, our results indicated that red orange juice anthocyanins were also absorbed from the small intestine. Two observations can be drawn from the in situ intestinal perfusion results. First, the intestinal absorption of Cy 3-malglc was almost double that of $\mathrm{Cy} 3$-glc, suggesting that acylation could favour intestinal absorption. Second, the absorption of Cy 3 -glc from red orange juice was lower than the absorption of purified Cy 3-glc or Cy 3-glc from blackberry or bilberry anthocyanin extract, which has been found to be about $20 \%$ using the same model (Talavéra et al. 2004). We have previously hypothesized (Talavéra et al. 2004) that anthocyanin glucosides, which have a basic flavonoid structure, could interact with the intestinal sodium-dependent glucose transporter 1 (SGLT1), as has been reported for quercetin glucosides (Walgren et al. 2000; Wolffram et al. 2002). The red orange juice extract used in these in situ experimentations contained a high amount of sugars. We have determined that the perfused solution contained $71 \mathrm{mM}$-glucose (compared with 12-mM in the intestinal buffer, as previously used during the perfusion of purified molecules (Talavéra et al. 2004)). We thus suggest that this high amount of glucose could lead to a competition-induced decrease in Cy 3-glc absorption via the SGLT1 carrier. Indeed, previous studies have shown that anthocyanin glucoside absorption was delayed and even decreased with a concomitant administration of sugar, and the authors have thus hypothesized that this pattern could result from a competitive action of glucose and anthocyanin glucosides on SGLT1 (Bub et al. 2001; Mulleder et al. 2002). However, this hypothesis requires further investigation to confirm the role of SGLT1 in anthocyanin glucoside absorption.

In conclusion, this study showed that red orange juice anthocyanins were rapidly absorbed from both stomach and small intestine and then excreted in the urine as intact and methylated forms. Moreover, absorption and metabolism were very similar between acylated anthocyanins and non-acylated anthocyanins. Future research will be aimed at investigating acylated anthocyanin distribution to various tissues and evaluating their potent biological activities.

\section{Acknowledgements}

This work was supported by funds from the Provincia Regionale di Catania (Italy), a research project on the antioxidant properties of Sicilian red oranges (Professor G. Galvano).

\section{References}

Bitsch I, Janssen M, Netzel M, Strass G \& Frank T (2004) Bioavailability of anthocyanidin-3-glycosides following consumption of elderberry extract and blackcurrant juice. Int J Clin Pharmacol Ther 42, 293-300.

Bub A, Watzl B, Heeb D, Rechkemmer G \& Briviba K (2001) Malvidin3 -glucoside bioavailability in humans after ingestion of red wine, dealcoholized red wine and red grape juice. Eur J Nutr 40, 113-120.

Cao G, Muccitelli HU, Sanchez-Moreno C \& Prior RL (2001) Anthocyanins are absorbed in glycated forms in elderly women: a pharmacokinetic study. Am J Clin Nutr 73, 920-926. 
Cooney JM, Jensen DJ \& McGhie TK (2004) LC-MS identification of anthocyanins in boysenberry extract and anthocyanin metabolites in human urine following dosing. J Sci Food Agric 84, 237-245.

Crespy V, Morand C, Besson C, Manach C, Demigné C \& Rémésy C (2002) Quercetin, but not its glycosides, is absorbed from the rat stomach. J Agric Food Chem 50, 618-621.

Dugo P, Mondello L, Morabito D \& Dugo G (2003) Characterization of the anthocyanin fraction of Sicilian blood orange juice by microHPLC-ESI/MS. J Agric Food Chem 51, 1173-1176.

Felgines C, Talavéra S, Gonthier MP, Texier O, Scalbert A, Lamaison JL \& Rémésy C (2003) Strawberry anthocyanins are recovered in urine as glucuro- and sulfoconjugates in humans. J Nutr 133, 1296-1301.

Felgines C, Texier O, Besson C, Fraisse D, Lamaison JL \& Rémésy C (2002) Blackberry anthocyanins are slightly bioavailable in rats. J Nutr 132, 1249-1253.

Felgines C, Texier O, Morand C, Manach C, Scalbert A, Régerat F \& Rémésy C (2000) Bioavailability of the flavanone naringenin and its glycosides in rats. Am J Physiol 279, G1148-G1154.

Fimognari C, Berti F, Nusse M, Cantelli-Forti G \& Hrelia P (2004) Induction of apoptosis in two human leukemia cell lines as well as differentiation in human promyelocytic cells by cyanidin-3-Obeta-glucopyranoside. Biochem Pharmacol 67, 2047-2056.

Fleschhut J, Kratzer F, Rechkemmer G \& Kulling SE (2006) Stability and biotransformation of various dietary anthocyanins in vitro. Eur J Nutr, 45, 7-18.

Frank T, Netzel M, Strass G, Bitsch R \& Bitsch I (2003) Bioavailability of anthocyanidin-3-glucosides following consumption of red wine and red grape juice. Can J Physiol Pharmacol 81, 423-435.

Galvano F, La Fauci L, Lazzarino G, Fogliano V, Ritieni A, Ciappellano S, Battistini NC, Tavazzi B \& Galvano G (2004) Cyanidins: metabolism and biological properties. J Nutr Biochem 15, 2-11.

Giusti MM \& Wrolstad RE (2003) Acylated anthocyanins from edible sources and their applications in food systems. Biochem Eng J 14, $217-225$.

Griffiths LA \& Smith GE (1972) Metabolism of myricetin and related compounds in the rat. Metabolite formation in vivo and by the intestinal microflora in vitro. Biochem J 130, 141-151.

Harada K, Kano M, Takayanagi T, Yamakawa O \& Ishikawa $\mathrm{F}$ (2004) Absorption of acylated anthocyanins in rats and humans after ingesting an extract of Ipomoea batatas purple sweet potato tuber. Biosci Biotechnol Biochem 68, 1500-1507.

Hillebrand S, Schwarz M \& Winterhalter P (2004) Characterization of anthocyanins and pyranoanthocyanins from blood orange [Citrus sinensis (L.) Osbeck] juice. J Agric Food Chem 52, 7331-7338.

Ichiyanagi T, Rahman MM, Kashiwada Y, Ikeshiro Y, Shida Y, Hatano Y, Matsumoto H, Hirayama M, Tsuda T \& Konishi T (2004) Absorption and metabolism of delphinidin 3-O-beta-D-glucopyranoside in rats. Free Radic Biol Med 36, 930-937.

Ichiyanagi T, Shida Y, Rahman MM, Hatano Y, Matsumoto H, Hirayama M \& Konishi T (2005) Metabolic pathway of cyanidin 3O-beta-D-glucopyranoside in rats. J Agric Food Chem 53, 145-150.

Kay CD, Mazza G, Holub BJ \& Wang J (2004) Anthocyanin metabolites in human urine and serum. Br J Nutr 91, 933-942.

Kühnau J (1976) The flavonoids. A class of semi-essential food components: their role in human nutrition. World Rev Nutr Diet 24, $117-191$.

Lee HS (2002) Characterization of major anthocyanins and the color of red-fleshed Budd Blood orange (Citrus sinensis). J Agric Food Chem 50, 1243-1246.

McGhie TK, Ainge GD, Barnett LE, Cooney JM \& Jensen DJ (2003) Anthocyanin glycosides from berry fruit are absorbed and excreted unmetabolized by both humans and rats. J Agric Food Chem 51, $4539-4548$.

Matsumoto H, Inaba H, Kishi M, Tominaga S, Hirayama M \& Tsuda T (2001) Orally administered delphinidin 3-rutinoside and cyanidin 3-rutinoside are directly absorbed in rats and humans and appear in the blood as the intact forms. J Agric Food Chem 49, 1546-1551.

Mazza G, Kay CD, Cottrell T \& Holub BJ (2002) Absorption of anthocyanins from blueberries and serum antioxidant status in human subjects. J Agric Food Chem 50, 7731-7737.

Miyazawa T, Nakagawa K, Kudo M, Muraishi K \& Someya K (1999) Direct intestinal absorption of red fruit anthocyanins, cyanidin-3glucoside and cyanidin-3,5-diglucoside, into rats and humans. $J$ Agric Food Chem 47, 1083-1091.

Mulleder U, Murkovic M \& Pfannhauser W (2002) Urinary excretion of cyanidin glycosides. J Biochem Biophys Methods 53, 61-66.

Nielsen IL, Dragsted LO, Ravn-Haren G, Freese R \& Rasmussen SE (2003) Absorption and excretion of black currant anthocyanins in humans and Watanabe heritable hyperlipidemic rabbits. J Agric Food Chem 51, 2813-2820.

Passamonti S, Vrhovsek U \& Mattivi F (2002) The interaction of anthocyanins with bilitranslocase. Biochem Biophys Res Commun 296, 631-636.

Passamonti S, Vrhovsek U, Vanzo A \& Mattivi F (2003) The stomach as a site for anthocyanins absorption from food. FEBS Lett 544, 210-213.

Powell DW \& Malawer SJ (1968) Relationship between water and solute transport from isosmotic solutions by rat intestine in vivo. Am J Physiol 215, 49-55.

Renaud S \& de Lorgeril M (1992) Wine, alcohol, platelets, and the French paradox for coronary heart disease. Lancet 339, 1523-1526.

Suda I, Oki T, Masuda M, Nishiba Y, Furuta S, Matsugano K, Sugita K \& Terahara N (2002) Direct absorption of acylated anthocyanin in purple-fleshed sweet potato into rats. J Agric Food Chem 50, $1672-1676$

Talavéra S, Felgines C, Texier O, Besson C, Gil-Izquierdo A, Lamaison JL \& Rémésy C (2005) Anthocyanin metabolism in rats and their distribution to digestive area, kidney, and brain. $J$ Agric Food Chem 53, 3902-3908.

Talavéra S, Felgines C, Texier O, Besson C, Lamaison JL \& Rémésy C (2003) Anthocyanins are efficiently absorbed from the stomach in anesthetized rats. J Nutr 133, 4178-4182.

Talavéra S, Felgines C, Texier O, Besson C, Manach C, Lamaison JL \& Rémésy C (2004) Anthocyanins are efficiently absorbed from the small intestine in rats. $J$ Nutr 134, 2275-2279.

Talavéra S, Felgines C, Texier O, Besson C, Mazur A, Lamaison J-L \& Rémésy C (2006) Bioavailability of a bilberry anthocyanin extract and its impact on plasma antioxidant capacity in rats. J Sci Food Agric 86, 90-97.

Tsuda T, Horio F \& Osawa T (1998) Dietary cyanidin 3-O-betaD-glucoside increases ex vivo oxidation resistance of serum in rats. Lipids 33, 583-588.

Tsuda T, Horio F \& Osawa T (1999) Absorption and metabolism of cyanidin 3-O-beta-D-glucoside in rats. FEBS Lett 449, 179-182.

Walgren RA, Lin JT, Kinne RK \& Walle T (2000) Cellular uptake of dietary flavonoid quercetin $4^{\prime}$-beta-glucoside by sodium-dependent glucose transporter SGLT1. J Pharmacol Exp Ther 294, 837-843.

Wang J \& Mazza G (2002) Effects of anthocyanins and other phenolic compounds on the production of tumor necrosis factor alpha in LPS/IFN-gamma-activated RAW 264.7 macrophages. J Agric Food Chem 50, 4183-4189.

Wolffram S, Block M \& Ader P (2002) Quercetin-3-glucoside is transported by the glucose carrier SGLT1 across the brush border membrane of rat small intestine. J Nutr 132, 630-635.

Wu X, Cao G \& Prior RL (2002) Absorption and metabolism of anthocyanins in elderly women after consumption of elderberry or blueberry. J Nutr 132, 1865-1871.

Youdim KA, McDonald J, Kalt W \& Joseph JA (2002) Potential role of dietary flavonoids in reducing microvascular endothelium vulnerability to oxidative and inflammatory insults. $J$ Nutr Biochem 13, 282-288. 